\title{
Editorial
}

\section{Hospitalised for Chronic Obstructive Pulmonary Disease: On a Dangerous Route}

\author{
Jørgen Vestbo \\ Department of Respiratory Medicine, Odense University Hospital, University of Southern Denmark, \\ Odense, Denmark
}

In this issue of Respiration, Slenter et al. [1] report on the prognosis of patients following hospital admission for an exacerbation of chronic obstructive pulmonary disease (COPD). In this setting of a Dutch University Medical Center, well known for its excellent COPD research, 1 in 4 patients had died within 1 year of discharge after an exacerbation of COPD and half of those surviving had been rehospitalised at least once.

Although scary these numbers come as no surprise. Statistics from the same institution 10 years earlier showed a 1-year mortality of $23 \%$ and 1 -year readmission rate of 55\% [2] and this is in line with findings from comparable settings $[3,4]$. Very few other acute medical admissions carry such a grave prognosis and it makes you wonder whether hospitalised COPD patients are given the attention they require - not that they are poorly managed by health professionals, but rather that health systems seem unable to provide them with both acute and sufficient continued health care management. One could argue that the severity of disease in these patients was such that their prognosis would have been poor even if not admitted. However, the fatality associated with a hospitalisation actually amounts to more than half of the mortality observed in a recent study [5] underlining the severity of a severe exacerbation.

The paper by Slenter et al. [1] focuses on predictors of mortality. A number of easily assessable factors are iden- tified and discussed. Not surprisingly, age, male gender and comorbidities were associated with a poor prognosis. A previous hospital admission was also a marker of a poor prognosis, which is not surprising given both the poor prognosis and high risk of readmission seen in this study as well as the previous report from the same institution $[1,2]$. However, it also demonstrates that having exacerbations - even severe ones - is a trait of significance or a phenotype in line with having frequent exacerbations. Markers of hypercapnic respiratory failure; i.e. arterial $\mathrm{pH}$ and $\mathrm{P}_{\mathrm{a}} \mathrm{CO}_{2}$, are usually markers of a poor prognosis, and both were associated with mortality in univariate analyses and a $\mathrm{P}_{\mathrm{a}} \mathrm{CO}_{2}>6.0 \mathrm{kPa}$ remained significantly associated with mortality in the multivariate model. Interestingly, urea $>8.0 \mathrm{mmol} / \mathrm{l}$ was associated with an increased risk of death. An elevated urea level is also an indicator in the pneumonia risk score, CURB65, and a recent paper actually showed that CURB65 works well in risk assessment of patients admitted with a severe exacerbation of COPD [6].

Taken together, the findings presented by Slenter et al. [1] point to the necessity of standardised evaluation of patients admitted with an exacerbation of COPD for the purpose of stratifying both acute and chronic care according to risk factor profiles. In this area - as in so many others - one size does not fit all and it is indeed time for us to act accordingly.

\section{KARGER}

Fax +41613061234

E-Mail karger@karger.ch

www.karger.com (c) 2012 S. Karger AG, Basel

$0025-7931 / 13 / 0851-0011 \$ 38.00 / 0$

Accessible online at:

www.karger.com/res
Jørgen Vestbo

Respiratory Research Group, Manchester Academic Health Sciences Centre

University Hospital South Manchester NHS Foundation Trust

University of Manchester, Manchester M23 9LT (UK)

E-Mail jvestbo@man.ac.uk 


\section{References}

-1 Slenter RHJ, Sprooten RTM, Kotz D, Wesseling G, Wouters EFM, Rohde GGU: Predictors of 1-year mortality at hospital admission for acute exacerbations of chronic obstructive pulmonary disease. Respiration 2013;85:15-26.

- 2 Groenewegen KH, Schols AMWJ, Wouters EFM: Mortality and mortality-related factors after hospitalization for acute exacerbation of COPD. Chest 2003;124:459-467.
3 McGhan R, Radcliff T, Fish R, Sutherland ER, Welsh C, Make B: Predictors of rehospitalization and death after a severe exacerbation of COPD. Chest 2007;132:1748-1755.

4 Eriksen N, Vestbo J: Management and survival of patients admitted with an exacerbation of COPD: comparison of two Danish patient cohorts. Clin Respir J 2010;4:208-214.
5 Hoogendoorn M, Hoogenveen RT, Ruttenvan Mölken MP, Vestbo J, Feenstra TL: Casefatality of COPD exacerbations: a meta-analysis and statistical modelling approach. Eur Respir J 2011;37:508-515.

- 6 Chang CL, Sullivan GD, Karalus NC, Mills GD, McLachlan JD, Hancox RJ: Predicting early mortality in acute exacerbation of chronic obstructive pulmonary disease using the CURB65 score. Respirology 2011;16: 146-151. 